http://dx.doi.org/10.30681/23588403v13i0211

\title{
AVALIAÇÃO DA APRENDIZAGEM EM LÍNGUA INGLESA: REFLEXÕES SOBRE CRENÇAS DE PROFESSORES EM FORMAÇÃO
}

Data de recebimento: $31 / 03 / 2020$ Aceite: 09/05/2020

Márcia Aparecida SILVA (UEG) ${ }^{1}$ Raquel Pereira GONÇALVES (UEG) ${ }^{2}$

\begin{abstract}
Resumo: O presente artigo, realizado como trabalho de conclusão do curso de Letras e situado na área de Linguística Aplicada, objetivou investigar crenças de alunos do curso de Letras, de uma universidade pública do interior do Estado de Goiás, sobre avaliação da aprendizagem da língua inglesa. A coleta de dados foi realizada por meio de um questionário respondido por professores em formação do último período do curso de Letras. A partir das análises, constatamos que, embora a maioria dos professores em formação ainda apresentem algumas concepções tradicionais de avaliação, eles demonstram conhecimento da importância de se buscar modelos de avaliação formativa. Com esse estudo, portanto, percebemos a importância de se analisar e refletir sobre as crenças de professores em formação como uma possibilidade de desenvolver uma postura crítico-reflexiva nos mesmos.
\end{abstract}

Palavras-chave: Crenças. Avaliação. Língua Inglesa.

\begin{abstract}
This article, presented as an undergraduate thesis and located within the field of Applied Linguistics, aimed to investigate beliefs of student-teachers from Letras course of a public University in the State of Goiás, on learning assessment of English language, reflecting on the importance/implication of this study to teacher education. The data were collected by means of a questionnaire answered by student-teachers from the last year of Letras. From the analysis, we have noticed that the majority of student-teachers demonstrate awareness on the importance of looking for different ways to assess learning. With this study, we could also notice the importance of analyzing and reflecting on beliefs of student-teachers in teacher training courses.
\end{abstract}

Keywords: Beliefs. Assessment. English Language.

\section{Introdução}

Muito se tem discutido atualmente sobre o conceito de avaliação e sobre sua importância no processo de ensino-aprendizagem (LUCKESI, 2002, 2011; HADJI, 2001, KENSKI, 2005). Embora a temática da avaliação seja bastante antiga e tenha sido bastante

\footnotetext{
${ }^{1}$ Doutora em Estudos Linguísticos pela Universidade Federal de Uberlândia e Mestre em Estudos Linguísticos pela mesma instituição. Graduada em Letras pela Faculdade de Filosofia e Ciências Humanas de Goiatuba. marciasilva@ueg.br

$\frac{1}{2}$ Graduada em Letras pela Universidade Estadual de goiás UEG-campus Iporá (UEG). raquelpg.letras@gmail.com
} 
pesquisada no âmbito da Linguística Aplicada e da Educação, percebemos que muitos ainda são os desafios enfrentados nesse campo no espaço escolar, tendo em vista que avaliação nem sempre tem servido ao objetivo de contribuir com a aprendizagem dos alunos, mas tão somente de classificar ou excluir, reforçando práticas tradicionais que a afastam de seu real objetivo.

Desse modo, práticas avaliativas tradicionais têm sido perpetuadas no fazer pedagógico de muitos professores de língua inglesa, as quais podem ter sido influenciadas pelas crenças que eles apresentam sobre avaliação. Por permanecerem desconhecidas, tais crenças podem impossibilitar que os professores repensem sua prática e, consequentemente, busquem mudanças necessárias. Diante disso, propomos as seguintes perguntas de pesquisa para este trabalho: quais as crenças de professores em formação sobre avaliação da aprendizagem de língua inglesa? Quais as implicações de tais crenças para a formação de professores?

Nesse sentido, a presente pesquisa centrou-se na investigação específica de crenças de professores em formação sobre avaliação da aprendizagem em língua inglesa. Para tanto, enviamos um questionário aberto à uma turma do oitavo período do curso de Letras PortuguêsInglês licenciatura, cujos alunos já leram estudos e teorias sobre avaliação da aprendizagem e tiveram a oportunidade de discutir/refletir sobre o tema de maneira sistemática, além de construir avaliações por meio de tecnologias digitais nas aulas da disciplina de Língua Inglesa V.

Para desenvolver o tema, dividimos este artigo em três partes: na primeira, discutimos o conceito de avaliação, os tipos existentes e as pesquisas na área; na segunda, discutimos o conceito de crenças, sua natureza e pesquisas na área também; e, por fim, a análise do questionário realizado com os professores em formação, em que apresentamos suas crenças e analisamos os dados com base nas teorias apresentadas.

\section{Avaliação da aprendizagem: um desafio constante}

Embora a avaliação da aprendizagem esteja presente no cotidiano de escolas e universidades, percebe-se que a prática avaliativa das instituições nem sempre está em sintonia com as reflexões e pesquisas desenvolvidas na área. Tal fato faz com que a avaliação da aprendizagem, de acordo com Luckesi (2002), seja tratada como sinônimo de exame, sendo utilizada apenas para classificar. O problema de se entender a avaliação dessa maneira, é que se desconsidera a aprendizagem do aluno, que é o objetivo principal da ação docente, como afirma Kenski (2005), contribuindo unicamente para a exclusão daqueles alunos que não 
conseguirem atingir uma determinada nota. Diante disso, é importante manter sempre em mente o que é avaliação da aprendizagem e qual é o seu papel no processo de ensino-aprendizagem.

Para Kenski (2005), a avaliação é parte integrante e substantiva do processo de ensinoaprendizagem, tratando-se de um momento de reflexão e de tomada de decisões e, portanto, de um processo de investigação permanente que orienta a prática. Em consonância com a pesquisadora, Luckesi (2002, p. 81) afirma que

[...] a avaliação deverá ser assumida como um instrumento de compreensão do estágio em que se encontra o aluno, tendo em vista tomar decisões suficientes e satisfatórias para que possa avançar no seu processo de aprendizagem.

Nesse sentido, a avaliação da aprendizagem não pode ser considerada como um fim em si mesma, uma vez que tem como papel principal nortear a prática pedagógica, de modo a ajudar o professor a verificar se os seus objetivos de aprendizagem estabelecidos para seus alunos estão sendo atingidos ou não, e caso não estejam, possibilitar que este possa redirecionar sua prática.

Segundo Hadji (2001), há basicamente três tipos de avaliação, de acordo com sua função e com o momento em que é realizada no processo de ensino e aprendizagem, a saber: a diagnóstica (ou prognóstica), que tem o objetivo de verificar o conhecimento prévio do aluno sobre determinado conhecimento ou habilidade, costuma ser ministrada do início do curso ou conteúdo em que o professor queira saber o nível dos alunos; a somativa (ou cumulativa), que tem o objetivo de apresentar um resultado, sendo ministrada geralmente no fim de um curso; e a formativa, que é uma forma contínua de avaliação, que se enfoca mais no processo do que nos resultados. Esse último tipo de avaliação é ministrado geralmente no decorrer do curso e não tem como objetivo fornecer uma nota, mas saber o que o aluno aprendeu do conteúdo visto, para direcionar as ações do professor.

Apesar de cada um dos tipos de avaliação mencionados por Hadji (2001) ser importante, considerando que possuem funções e momentos diferentes, podemos afirmar que a avaliação formativa é o coração de todo o processo de avaliação, tendo em vista que o principal objetivo do ato de avaliar é promover a aprendizagem dos educandos. Tal afirmação pode ser confirmada a partir de pesquisas que enfatizam a avaliação formativa para o processo de ensinoaprendizagem de línguas, como é o caso da pesquisa de Silva (2014), que defende a inserção do diário reflexivo nas aulas de língua inglesa como ferramenta de avaliação formativa. Para a autora, essa inserção pode colaborar com a aprendizagem dos alunos, uma vez que estes podem 
se tornar mais conscientes de que também são responsáveis por sua aprendizagem. Podemos ainda mencionar Silva (2018) que, em sua pesquisa de doutorado, investiga as representações de professores em formação sobre a integração de tecnologias digitais para avaliar a aprendizagem, defendendo a avaliação formativa como uma maneira de colaborar para com a aprendizagem dos alunos

A pesquisa de Fidalgo (2006) investiga a forma como a avaliação pode ser processual e não produto final. Para a autora, a avaliação, como processo, passa a fazer parte da aprendizagem dos alunos, e o professor pode utilizá-la também para saber como está o seu próprio desempenho e, a partir daí, criar as estratégias que julgar necessárias para contribuir com a aprendizagem dos alunos.

Diante do exposto, é evidente que a avaliação é uma parte imprescindível do processo de ensino-aprendizagem, devendo ser integrada a ele de modo a atingir o seu principal objetivo, que é promover a aprendizagem dos alunos, e não apenas classificá-los ou fornecer notas e resultados. Nessa perspectiva, acreditamos que, ainda que não possamos dispensar os modelos de avaliação somativa e diagnóstica, que estão mais centradas em resultados e são mais específicas de um momento, é importante priorizar o processo, buscando modelos de avaliação formativa, os quais podem realmente contribuir para que o aluno supere gradativamente suas dificuldades e evolua em seu aprendizado. Assim, consideramos relevante discutir sobre avaliação neste trabalho, haja vista sua importância na educação e as muitas dificuldades ainda enfrentadas para que ela contribua, de fato, com a aprendizagem dos alunos.

\section{Crenças: conceito, natureza e importância para a avaliação da aprendizagem}

Embora o conceito de crenças pareça simples, talvez pelo fato de ser naturalmente relacionado com a religião, ou talvez pela definição do senso comum de que "crença é algo em que se acredita", é importante esclarecer que o seu conceito adquiriu novos significados ao ser estudado na Linguística Aplicada. Foi inclusive situado por Barcelos (2006) dentro da área da cognição, revelando-se tratar de um conceito muito mais complexo do que se imagina em um primeiro momento.

De acordo com Barcelos (2006), em sua pesquisa de crenças sobre ensinoaprendizagem de línguas na década de 90 no Brasil, acreditava-se que as crenças eram estruturas mentais, estáveis e fixas, localizadas dentro da mente das pessoas e distintas do conhecimento, sendo muitas vezes as crenças de alunos ou professores julgadas como certas ou erradas. No entanto, como a pesquisadora aponta, os desenvolvimentos ocorridos na área da cognição, 
influenciaram as visões recentes com relação à natureza de crenças, indicando uma visão mais contextual do conceito, não mais de natureza estática e fixa, como se acreditava anteriormente. Das muitas definições existentes, nos ancoramos na concepção de Barcelos (2006, p. 18), que entende crenças como:

[...] uma forma de pensamento, como construções da realidade, maneiras de ver e perceber o mundo e seus fenômenos, co-construídas em nossas experiências e resultantes de um processo interativo de interpretação e re (significação). Como tal, crenças são sociais (mas também individuais), dinâmicas, contextuais e paradoxais.

Com base nessa definição é possível perceber a complexidade presente no conceito de crenças. Em oposição à ideia de que crenças são estruturas fechadas e fixas na cabeça de uma pessoa, aqui entendemos, com base em Barcelos (2006), que elas também se constroem socialmente por meio da interação com outras pessoas. Além disso, por serem dinâmicas e contextuais, entendemos que elas podem sofrer mudanças e se diferenciar, dependendo das experiências de um indivíduo e de suas interações com o ambiente. E, ainda, pelo fato de serem paradoxais, "as crenças podem agir como instrumentos de empoderamento ou como obstáculos para o ensino/aprendizagem de línguas" (BARCELOS, 2000, 2003 apud Barcelos, 2006, p.20). Devido a essa natureza múltipla das crenças, há atualmente várias pesquisas na área, que se concentram em seus diferentes aspectos.

Segundo Barcelos (2006), as pesquisas atuais sobre crenças se concentram, principalmente, em sua relação com o contexto e as experiências, seu papel na reflexão e na tomada de decisão de professores e também em aspectos específicos da área de ensinoaprendizagem de línguas, tais como: gramática, leitura, bom professor, bom aprendiz, correção de erros, linguagem lúdica, tradução, vocabulário e ensino de vocabulário, motivação, avaliação e oralidade.

Quanto às pesquisas sobre crenças que exploram aspectos específicos do processo de ensino-aprendizagem de línguas, podemos mencionar os estudos de Malatér (2007), que teve como objetivo investigar as crenças de alunos ingressantes no Curso de Letras Português/Inglês sobre o desenvolvimento da competência oral na língua estrangeira. $\mathrm{O}$ autor defende que o levantamento e acompanhamento dessas crenças são importantes para o entendimento das necessidades dos acadêmicos, o que permite melhor capacitá-los a lidar com a oralidade de maneira adequada em sua futura prática profissional na Educação Básica. Alvarez (2007) estudou as crenças e motivações de alunos em formação pré-serviço, destacando o estudo das crenças como imprescindível para o entendimento da forma como as pessoas pensam e "do 
porquê aceitamos algumas coisas como verdadeiras em vez de pensar que essas coisas podem ser questionadas no futuro" (ALVAREZ, 2007, p.196).

A nossa pesquisa, que também explora o conceito de crenças no processo de ensinoaprendizagem de línguas, centrou-se especificamente nas crenças de professores em formação sobre avaliação da aprendizagem de língua inglesa, exclusivamente de professores-alunos que estão no último ano de formação e já tiveram acessos a conceitos sobre avaliação da aprendizagem. Entendemos que o estudo de crenças sobre avaliação tem muito a contribuir com a formação dos futuros professores, uma vez que permite que eles repensem a avaliação e, ao mesmo tempo, sua prática pedagógica. Assim como aponta Alvarez (2007, p. 194):

Os cursos de formação precisam fornecer subsídios para que o profissional tenha autonomia, discernimento e capacidade de refletir a respeito dos problemas com os quais se depara em sua prática e assim possa construir alternativas teórico-metodológicas adequadas e não somente aplicar técnicas pré-estabelecidas.

Portanto, é importante pensar nas crenças dos professores em formação, pois essa é a maneira de perceber o que precisa ser melhorado nos cursos de formação de professores para garantir que os futuros professores sejam capazes de refletir sobre suas práticas, principalmente no que diz respeito à avaliação, quando estiverem exercendo a profissão. Do contrário, corremos o risco de formar professores que apenas repetem técnicas sem considerar ou refletir sobre as implicações delas no aprendizado dos alunos.

\section{Metodologia}

Segundo Abrahão (2006), há diferentes abordagens e instrumentos de pesquisa que vêm sendo utilizados nos estudos que têm por foco a investigação de crenças sobre ensinar e aprender. Barcelos (2001 apud Abrahão, 2006), divide os estudos de crenças em três grandes abordagens: abordagem normativa, que entende as crenças como ideias pré-concebidas que influenciam na abordagem de ensino-aprendizagem; abordagem meta-cognitiva, que conceitua crenças como conhecimento meta-cognitivo; e a abordagem contextual, na qual as crenças são inferidas de ações contextualizadas. Para cada uma das abordagens mencionadas, corresponde um tipo de instrumento de coleta de dados.

Para realização deste trabalho, que é de natureza qualitativa e teve como objetivo investigar as crenças de professores em formação sobre o que é a avaliação da aprendizagem de língua inglesa, optamos pela abordagem meta-cognitiva, dado que construímos uma 
entrevista semiestruturada para os participantes, em que eles podiam responder às perguntas e falar sobre temas que lhes interessasse. Segundo Abrahão (2006, p. 219) “o conhecimento metacognitivo é concebido como teorias de ação, que ajudam os participantes a refletirem sobre suas ações e potenciais para a aprendizagem e/ou para o ensino".

Os sujeitos participantes da pesquisa são alunos do oitavo período do curso de Letras Português-Inglês licenciatura, de uma instituição pública do interior do Estado de Goiás, que já tiveram acesso a teorias e construção de avaliações na disciplina de Língua Inglesa V, quando participaram de uma pesquisa sobre a integração de tecnologias digitais para avaliar a aprendizagem. Assim, ressaltamos que os participantes tiveram acesso aos conceitos de avaliação da aprendizagem antes da presente pesquisa.

Para a coleta dos dados, enviamos um questionário por meio da plataforma digital Google Forms (Plataforma de construção de formulários) aos participantes, os quais escolheram um pseudônimo como forma de preservar sua identidade. O questionário foi formado pelas seguintes perguntas: 1) O que é avaliar para você? 2) Como você considera a forma em que foi avaliado em sua trajetória acadêmica? 3) De que maneiras o professor pode avaliar a aprendizagem de seus alunos?

É importante destacar que enfrentamos alguns desafios na coleta de dados, pois, embora a turma seja formada por 13 alunos, apenas 8 deles responderam ao questionário, e destes, alguns responderam de maneira tão sucinta e vaga, que não foi possível mapear suas crenças. No entanto, por se tratar de uma pesquisa qualitativa, mesmo com essas dificuldades, conseguimos apresentar uma discussão sobre a temática que nos propomos estudar, apresentando muitas conclusões válidas.

\section{Análise e discussão dos dados}

A partir do entendimento das implicações, abrangência e complexidade do conceito de avaliação da aprendizagem, bem como do conceito de crenças, partiremos agora para a análise das respostas dos professores em formação coletadas por meio do questionário. É importante ressaltar que optamos por apresentar nos quadros apenas excertos das respostas mais representativas de cada crença mapeada, sendo que as demais respostas que consideramos pertinentes foram apresentadas no corpo do texto.

Quadro 1: crenças referentes às perguntas 1 e 2

Pergunta 1: O que é avaliar? 


\begin{tabular}{|l|c|}
\hline \multicolumn{1}{|c|}{ Excertos } & \multicolumn{1}{|c|}{ Crenças } \\
\hline $\begin{array}{l}\text { Quando quero verificar a habilidade de conhecimento ou aprendizagem de algo } \\
\text { estabelecido. ( Deby) }\end{array}$ & $\begin{array}{c}\text { Avaliar é } \\
\text { verificar } \\
\text { resultados }\end{array}$ \\
Verificação da aprendizagem (Eny) & Avaliar é verificar se o aluno conseguiu absorver o conteúdo ensinar. (Alice) \\
\hline Pergunta 2: De que formas o professor pode avaliar? & $\begin{array}{c}\text { É importante } \\
\text { ter ferramentas } \\
\text { diversas para } \\
\text { avaliar }\end{array}$ \\
\hline Autoavaliação, participação em atividades. (Deby) & $\begin{array}{l}\text { Por seminário, participação na sala de aula. (Eny) } \\
\text { Deve procurar a formas de avaliar onde o aluno não se sinta pressionado, deve } \\
\text { buscar formas diferente para avaliar e assim atingir todos seus alunos. (Alice) }\end{array}$ \\
\hline
\end{tabular}

Ao analisar as respostas dadas pela maioria dos professores em formação à questão 1, que se trata do conceito que eles têm de avaliação, identificamos/mapeamos a crença de que avaliar é verificar resultados, conceito que remete ao modelo de avaliação somativa, o qual, segundo Hadji (2001), tem o objetivo de apresentar um resultado. Embora o verbo "verificar" também pudesse remeter ao modelo de avaliação diagnóstica, a qual, de acordo com o mesmo autor, está relacionada ao conhecimento prévio dos alunos, o uso do termo "resultados" ou dos verbos no passado remetem ao fim de um processo, o que pode indicar que os sujeitos da pesquisa não se referiram à avaliação diagnóstica.

Ana Júlia definiu avaliar como "certificar se o que você está ensinando os alunos estão aprendendo", revelando a crença de que avaliar é certificar, que se trata de um sinônimo de verificação. No entanto, é interessante observar o uso do gerúndio. Em vez de escrever, "certificar se os alunos aprenderam o que o professor ensinou", que também remeteria à ideia de avaliação somativa, ela utilizou verbos que indicam uma ação em progresso, o que pode revelar que, por mais que não esteja explicitamente marcado no texto, ela pode ter pensado em uma avaliação formativa, a qual, segundo Hadji (2001), é uma forma contínua de avaliação que se enfoca mais no processo do que nos resultados, visando saber o que o aluno aprendeu com o objetivo de direcionar as ações do professor. Desse modo, ainda que Ana Júlia não demonstre uma preocupação explícita com o direcionamento das ações do professor, ela parece visualizar a avaliação como um processo. Por outro lado, a resposta dela também pode representar uma homogeneização, pois parece supor que os alunos aprendem da mesma forma. 
Para Amélie, avaliar é "entender o quê e qual conhecimento a pessoa adquiriu em um determinado tempo, para que o professor a partir de um processo cumulativo continue aplicando o conteúdo esperado". Embora o termo "cumulativo" aqui possa remeter à função somativa da avaliação, a qual tem o objetivo de apresentar um resultado no fim de um curso, parece-nos que a aluna defende a ideia de que é preciso compreender o conhecimento que o aluno já tem para que seja possível avançar para o próximo. Assim, ainda que ela tenha utilizado o termo cumulativo e a ideia de professor como aplicador de conteúdo, seu pensamento parece corresponder à ideia de "formativo", o que se confirma com sua resposta sobre os meios de avaliar, na questão 2. Amélie menciona como formas de avaliar: "Avaliação contínua e formativa, por meio de atividades de formação e não somente para tecer uma nota. Além disso, o professor pode avaliar os alunos de acordo com os mais variados fatores como: participação, engajamento e envolvimento com a disciplina, e avaliá-lo além da prova com notas". Ela apresenta uma visão mais aprofundada da avaliação e também entende que é preciso avaliar das mais diferentes formas.

As respostas dadas pela maioria dos professores em formação à questão 2 - de que formas o professor pode avaliar? - como é possível observar no quadro 1, indicam a crença de que é importante ter diferentes ferramentas para avaliar, não se restringindo à prova como instrumento avaliativo. Assim, são mencionadas inclusive "atividades de formação" (resposta de Amélie), participação em atividades e a autoavaliação, que, segundo Silva (2018, p. 46) é um modelo de avaliação que insere totalmente o aluno no processo, possibilitando que ele próprio reflita sobre o que aprendeu, "dando pistas aos professores sobre a dinâmica das aulas". As diferentes formas avaliativas mencionadas demonstram conhecimento prévio por parte dos sujeitos da pesquisa acerca das teorias de avaliação, que foram estudadas por eles. Desse modo, ainda que a prova também seja mencionada por um dos participantes, são apontados, em sua maioria, instrumentos avaliativos que remetem à avaliação formativa.

Sophie apresenta uma resposta interessante ao afirmar que o professor pode avaliar de várias formas, mas que ela preferiria não fazer a "tão misteriosa Prova". Nessa breve resposta, a participante demonstra alguma aversão à prova como instrumento avaliativo. E também aqui ficam as indagações: por que ela utiliza o adjetivo "misteriosa" e escreve prova com letra maiúscula? Seria uma maneira de expressar a soberania da prova no ambiente escolar, uma vez que ela geralmente é tratada como decisiva para a aprovação do aluno?

Ainda em resposta a essa pergunta, alguns alunos trouxeram outros pontos interessantes para discussão. Alice escreveu que "[o professor] deve procurar formas de avaliar 
onde o aluno não se sinta pressionado" e que atinja todos os alunos, o que demonstra a crença de que é preciso ouvir o aluno. Essa crença é importante, pois reforça a necessidade de se criar contextos de aprendizagem que realmente possibilitem ao aluno expressar os seus conhecimentos, afinal, segundo HADJI (2001, p. 36),

Os processos psicossociais complexos postos em jogo pela avaliação dependem não somente dos conteúdos em jogo, mas também das condições sociais da própria prova de avaliação. Por essa razão, com o mesmo equipamento intelectual, um aluno poderá produzir outros desempenhos se o contexto social for diferente

Levelyn não falou diretamente das formas, abordando aspectos de metodologia ao escrever que "Ele [o professor] precisa avaliar de acordo com a metodologia que ele usa para ensinar seus alunos", o que demonstra a crença de que ensino e avaliação são indissociáveis. Afirmando, logo em seguida, que o professor não pode "cobrar dos alunos aquilo que ele não soube ensinar", demonstrando a necessidade de o professor estabelecer critérios de avaliação que estejam relacionados aos objetivos de ensino. Além disso, ela ainda ressalta a necessidade de o professor "pensar em todos", provavelmente demonstrando, assim como Alice, a importância de personalização como forma de lidar com uma realidade heterogênea.

Ricardo também traz um pensamento interessante ao dizer que o professor pode avaliar "de maneiras em que o aluno possa externar o seu conhecimento sobre a determinada disciplina, ao invés de limitá-lo à algumas questões", mencionando a entrevista individual e a produção de textos como os instrumentos avaliativos que mais lhe deixou livre para expressar seus conhecimentos. Com essa resposta, Ricardo revela a crença de que questões fechadas, que caracterizam o modelo de prova tradicional, limitam o conhecimento do aluno, impedindo-o de mostrar o que realmente aprendeu.

É possível perceber, portanto, que embora os alunos não apresentem muitos exemplos de avaliação formativa, a maioria deles compreendem o seu conceito e importância no processo de ensino-aprendizagem. Tal conhecimento apresentado por eles pode ser resultado das teorias e discussões sobre avaliação a que tiveram acesso.

Com o intuito de ampliar nossa percepção acerca das crenças que os professores em formação têm sobre avaliação, partindo da experiência deles como alunos, eles foram questionados: como você considera a forma em que foi avaliado em sua trajetória acadêmica?

A seguir, são apresentadas as suas respostas a essa pergunta.

Quadro 2: crenças referentes à pergunta 3 


\begin{tabular}{|l|c|}
\hline $\begin{array}{l}\text { Pergunta 3: como você considera a forma em que foi avaliado em sua } \\
\text { trajetória acadêmica? }\end{array}$ & Crenças \\
\hline $\begin{array}{l}\text { A avaliação no curso de Letras serve de exemplo porque ela tece uma } \\
\text { noção geral de conhecimento do aluno e não é baseada em atividades para } \\
\text { aplicar uma nota somente. Considero de forma justa a forma como venho } \\
\text { sido avaliada na minha trajetória acadêmica. (Amélie) }\end{array}$ & $\begin{array}{c}\text { Avaliar é } \\
\text { estabelecer/aplicar um } \\
\text { conceito de justiça }\end{array}$ \\
\hline $\begin{array}{l}\text { Sortida, pois um ambiente universitário, ao contrário do ensino básico, o } \\
\text { professor possui uma autonomia quanto a sua forma de avaliar seus } \\
\text { alunos. Seja por meio de um questionário (prova), pela elaboração de um } \\
\text { texto (artigo/resumo/resenha), seminários de obras, dentre } \\
\text { outros.(Ricardo) }\end{array}$ & $\begin{array}{c}\text { A diversidade dos } \\
\text { tem relaçâa com a a } \\
\text { qualidade da avaliação }\end{array}$ \\
\hline
\end{tabular}

Como é possível observar no quadro 2, conseguimos identificar dois tipos de crenças para essa questão. Infelizmente, não foi possível analisar todas as respostas dadas à essa questão, uma vez que metade dos participantes da pesquisa apresentaram respostas muito objetivas, como "Algumas delas tensas", "Boa", "Não fiquei muito satisfeita", não sendo possível identificar crenças a serem discutidas. Além disso, percebemos que o uso do termo "trajetória acadêmica" na pergunta representou um problema, visto que todos participantes da pesquisa pareceram considerar apenas o ambiente universitário, quando gostaríamos que também considerassem suas experiências no ambiente escolar.

A partir da resposta de Amélie, que considera justa a forma como vem sendo avaliada em sua trajetória acadêmica, identificamos a crença de que avaliar é estabelecer um conceito de justiça. Tal conceito, na crença da participante, está relacionado com modelos de avaliação que buscam definir uma noção geral de conhecimento do aluno, não devendo ser baseadas apenas em atividades que visam notas. Com essa resposta, ela também revela a crença de que a nota é incapaz de representar fielmente o conhecimento do aluno, podendo ser, muitas vezes, injusta. Essa crença nos remete à teoria de Hadji (2001) que defende que avaliação não é apenas uma medida, visto que uma medida se trata de uma operação de descrição quantitativa de dados, sendo, portanto, de caráter objetivo. Considerando que a avaliação envolve fatores subjetivos, como as expectativas de um determinado professor, Hadji (2001) entende avaliação, portanto, como "uma interação, uma troca, uma negociação entre avaliador e um avaliado, sobre um objeto particular em um ambiente social dado" (HADJI, 2001, p. 34 apud WEISS, 1991, p.6).

Em resposta a essa mesma pergunta, identificamos ainda a crença de que a diversidade dos instrumentos avaliativos tem relação com a qualidade da avaliação, a qual se relaciona com a crença identificada na questão 2 de que é importante ter ferramentas diversas para avaliar. Por se tratar de uma pergunta diferente, a semelhança das crenças identificadas enfatiza a 
importância da diversidade de instrumentos avaliativos na crença dos professores em formação questionados. Ana Júlia, por exemplo, considerou ótimo o fato de ter sido avaliada de maneiras diversas em sua trajetória acadêmica.

Ricardo, ainda que não tenha emitido nenhum julgamento de valor, parece demonstrar a mesma crença de que é importante diversificar as formas de avaliar, pois considerou a forma como foi avaliado na universidade como "sortida", mencionando vários instrumentos avaliativos. Além disso, ele relaciona essa forma de avaliação diversificada ao fato de o professor possuir autonomia quanto às formas de avaliar seus alunos no ambiente universitário, algo que, em sua opinião, não acontece no ensino básico. Considerando que o aluno se trata de um professor em formação, que está sendo preparado para atuar também no ensino básico, essa crença nos leva a refletir: quais representações o levaram a acreditar que o professor do ensino básico não possui autonomia no que diz respeito à avaliação? Seriam os controles externos do governo? De que modo isso afeta sua visão de avaliação?

Sophie considerou a forma com que foi avaliada como "interessante" pelo fato de quase não ter feito provas, mencionando que seus professores avaliaram somente com o que aprendeu. Tal pensamento demonstra a crença de que a prova não lhe parece um instrumento adequado para avaliar a aprendizagem dos alunos, o que reforça sua aversão a esse instrumento avaliativo, apresentado por ela na questão 2. Sua resposta também pode revelar que ela foi muito avaliada por meio de provas na escola e que a quase inexistência delas no ensino superior representa algo positivo.

Desse modo, com base nas experiências dos professores em formação como alunos, percebe-se principalmente uma ênfase na crença de que é importante buscar formas diferentes de avaliar, não se limitando à prova, modelo de avaliação tradicional mais presente e conhecido na escola. Essa crença reforça a teoria defendida anteriormente de que "[...] a avaliação, como mediadora do processo de ensino-aprendizagem, precisa ser diversificada, para atender, minimamente a heterogeneidade de uma sala" (ALVES, 2016, p. 114).

Embora a avaliação, como apresentada neste trabalho, e como discutida por teóricos, tenha como objetivo geral contribuir para aprendizagem dos alunos, como bem apontaram alguns alunos, acreditamos ser importante pensar a avaliação de maneira específica também, visto as diferenças e particularidades de cada disciplina. Uma vez que se entende que é preciso métodos diferentes para ensinar uma língua estrangeira, logo, também é necessário pensar em maneiras de avaliar mais específicas, que condizem com os objetivos de ensino, visto que ensino e avaliação são tratados aqui como indissociáveis. 
Diante das respostas dos participantes nesta pesquisa, percebemos que os alunos ainda possuem alguns conceitos tradicionais de avaliação arraigados em sua mente, mas que ao mesmo tempo é possível perceber alguns pensamentos mais abertos, o que mostra que o trabalho específico com a avaliação dentro da disciplina de Língua Inglesa, contribuiu para uma ressignificação do conceito, ainda que pouca, o que evidencia, de acordo com SILVA (2018, p.39),

[...] a necessidade de se discutir avaliação da aprendizagem nos cursos de formação de professores para que não se perpetue uma avaliação considerada tradicional e que não atende àquilo que uma avaliação deveria priorizar: colaborar para a aprendizagem dos alunos.

A partir da discussão apresentada neste trabalho e das análises feitas, constatamos a importância de se analisar as crenças de professores em formação como uma possibilidade de desenvolver uma postura crítico-reflexiva nos mesmos. Embora tenhamos nos pautado apenas em analisar suas crenças, defendemos que o trabalho com as crenças dos professores em formação sobre avaliação da aprendizagem nos cursos de licenciatura pode promover um rico aprendizado.

\section{Considerações finais}

Tendo em vista que a avaliação, como discutida ao longo deste trabalho, é parte essencial e substantiva do processo de ensino-aprendizagem, faz-se necessário uma análise das crenças apresentadas por professores em formação, não apenas para identificá-las, mas para refletir sobre elas, analisá-las e compreender suas implicações nas práticas pedagógicas dos futuros professores.

Foi possível perceber que, ainda que os alunos revelem algumas concepções tradicionais, eles foram positivamente formados por meio da experiência com a avaliação da aprendizagem. Embora esta seja vista como um tema desgastado por grande parte dos educadores, observamos que sua discussão ainda é necessária, uma vez que muitas práticas tradicionais, que se mostram negativas em muitas pesquisas, continuam sendo realizadas em larga escala e sem reflexão.

Desse modo, entendemos neste trabalho que para uma melhor formação dos professores, seria de extrema e fundamental importância a existência de uma disciplina sobre avaliação da aprendizagem, que proporcionasse uma profunda reflexão do conceito e momentos de construção de avaliações com problematizações. No caso da língua inglesa, tal disciplina 
também poderia envolver reflexões sobre a língua, como forma de repensar maneiras de avaliar que não se centrassem apenas em gramática e tradução, mas que englobassem também as habilidades orais e aspectos culturais da língua estudada.

\section{Referências}

ALVES, A. C. Representações sobre o processo avaliativo de docentes de LE egressos do curso de Letras de uma universidade federal. In: SILVA, S. R; ALVES FILHO, Sebastião Carlúcio (Orgs.). Sobre avaliação e ensino de línguas: (re)discutindo conceitos e (re)elaborando ações. Campinas, SP: Pontes Editores, 2016.

ABRAHÃO, M. H. V. Metodologia na investigação das crenças. In: ABRAHÃO, M. H. V; BARCELOS, A. M. F. (orgs.). Crenças e ensino de línguas - foco no professor, no aluno e na formação de professores. Campinas, SP: Pontes Editores, 2006.

ALVAREZ, M. L. O. Crenças, motivações e expectativas de alunos de um curso de formação Letras/Espanhol. Linguística aplicada: múltiplos olhares. Brasília, DF: UnB-Universidade de Brasília/Finatec (2007): p. 191-232.

BARCELOS, A. M. F. Cognição de professores e alunos: tendências recentes na pesquisa de crenças sobre ensino e aprendizagem de línguas. In: ABRAHÃO, M. H. V; BARCELOS, A. M. F. (orgs.). Crenças e ensino de línguas - foco no professor, no aluno e na formação de professores. Campinas, SP: Pontes Editores, 2006.

FELICE, M. I. V. Qual o lugar da avaliação da aprendizagem na formação do Professor de línguas? In: Anais do XIII Simpósio Nacional de Letras e Linguística/ III Simpósio Internacional de Letras e Linguística. Universidade Federal de Uberlândia. Uberlândia, MG. De 23 a 25 de novembro de 2011. Disponível em: http://www.ileel.ufu.br/anaisdosilel/pt/arquivos/silel2011/2942.pdf. Site acessado em 04 de novembro de 2018.

FIDALGO, S. S. A Avaliação de ensino-aprendizagem: ferramenta para a formação de agentes críticos. Dissertação de Mestrado em Linguística Aplicada e Estudos da Linguagem. Pontifícia Universidade Católica de São Paulo, 175f, 2002.

HADJI, C. Avaliação desmistificada. Porto Alegre: Artmed, 2001.

KENSKI, V. M. Repensando a avaliação da aprendizagem. In: VEIGA, Ilma Passos Alencastro (Org.). Repensando a didática. 22. Ed. Campinas, SP: Papirus, 2005. p. 135-147. 
LEFFA, Vilson. Redes sociais: ensinando línguas como antigamente. In: ARAÚJO, Júlio, Leffa, Vilson (orgs.). Redes sociais e ensino de línguas: o que temos de aprender? São Paulo: Parábola Editorial, 2016.

LUCKESI, C. C. Avaliação da aprendizagem escolar: estudos e proposições. São Paulo: Cortez, 2002.

. Avaliação da aprendizagem componente do ato pedagógico. São Paulo: Cortez, 2011.

MALÁTER, L. S. O. A competência oral em inglês sob o olhar de futuros professores. In: ABRAhÃO, M. H. V.; GIL, G.; RAUBER, A. S. (Orgs.). Anais do I Congresso LatinoAmericano sobre Formação de Professores de Línguas. Florianópolis, UFSC, p. 642656, 2007.

SILVA, M. A. Diário reflexivo e avaliação formativa nas aulas de língua inglesa da educação básica: um estudo de caso. Dissertação de mestrado, Universidade Federal de Goiás, 2014, 124f.

M. A. Integração de tecnologias digitais para avaliar a aprendizagem em contexto presencial. Tese de doutorado. Universidade Federal de Uberlândia, 2018, $243 f$. 